\title{
The Dutch philosopher and historian Johan Huizinga described a way of looking at medieval thought in his book the waning of the middle ages:
}

\section{Editorial}

The naive religious conscience of the multitude had no need of intellectual proofs in matters of faith. The mere presence of a visible image of things holy sufficed to establish their truth. No doubts intervened between the sight of all those pictures and statues - the persons of the Trinity, the flames of hell, the innumerable saints and belief in their reality. All these conceptions became matters of faith in the most direct manner; they passed straight from the state of images to that of convictions, taking root in the mind as pictures clearly outlined and vividly colored, possessing all the reality claimed for them by the Church, and even a little more.

We can use mostly the same words to characterize the twentyfirst century human. Who could imagine, even at the end of the millennium, that the modern technological advancements of Internet and social media would catapult humankind back a thousand years in the span of a single decade to the darkest middle age - the post-truth era - a strange euphemism for a time when the truth is not true.

Since the renaissance, we have believed that science is a path to truth. Of course, the way is grievous and unsafe and can't be breezed through; every step and answer generates more questions and more trails not taken. But, by and large, the scientific method was accepted as the only way to the truth.

Certainly, even in the twentieth century, there were times and places where thinking and truth were replaced by blind faith and credulity- Nazi Germany and Bolshevik Russia, for instance. But all of them generated just hundreds of millions of corpses- not more.

Of course, conspiracy theorists, charlatans and various other outsiders have existed as long as humankind. A man on the street seeks simple answers to sophisticated questions, and he wants them now. Therefore, we see headlines such as Scientists have discovered a simple way to... in nearly every newspaper. Millions of healers, soothsayers, homeopaths, crystal therapists and ghost hunters earn fortunes in their booming businesses.

Scientific economics has never precisely forecast major crises. The reason is simple: in its calculations, market participants act as healthyminded, rational persons - when in fact they are not. There are many diseases that can be cured using contemporary medicine, but more that cannot-especially those that don't exist. But every self-appointed healer can cure them!

And the prescriptions are extremely simple. One example: to be healthy, the only thing you need is to eat a spoonful of baking soda (or something even more nonsensical) every day to raise your body's $\mathrm{pH}$ and thereby enjoy perfect wellness.

Everyone who has completed chemistry in elementary school should know that living organisms are homeostatic, trying to keep all their vital parameters unchanged. The $\mathrm{pH}$ of human blood is 7.4; if you
Volume I Issue I - 2017

Juri Liiv

Chemistry and materials, University of Tartu, Estonia

Correspondence: Juri Liiv, University of Tartu, chemistry and materials, Estonia,Tel +372 5283238, Email jyriliiv@gmail.com

Received: March 24, 2017 | Published: March 31, 2017

change it, you simply kill the person. Despite this simple knowledge, millions of people all over the world believe this nonsense. And the most important force encouraging such erroneous theories to prosper and spread is the aforementioned social media.

In this way, knowledge is replaced with myths and legends, just as in the middle ages. Ralph Keyes writes:

Post-truthfulness builds a fragile social edifice based on wariness. It erodes the foundation of trust that underlies any healthy civilization. When enough of us peddle fantasy as fact, society loses its grounding in reality. Society would crumble altogether if we assumed others were as likely to dissemble as tell the truth. We are perilously close to that point.

My current research is mainly focused on peat chemistry. Peat mining is a topic likewise covered by a carpet of lies and myths. Turf is considered to be a partially renewable resource (in suitable conditions the annual regrowth is $1 \mathrm{~mm}$, and its extraction rate in many countries far exceeds its regrowth rate). Therefore radical environmentalists declare, "Leave the mires alone!"

But this is mythical thinking. The reality is much more complicated.

In northern countries (such as Estonia, where I live) peat was mined for hundreds of years. The peat lands were drained, but only the higher, less decomposed strata were extracted. Most of the decomposed peat remains unused in the nature. The organic carbon, which has built up over thousands of years and is normally underwater, is suddenly exposed to the air. It decomposes and turns into carbon dioxide, which is released into the atmosphere. In Estonia the quantity of $\mathrm{CO}_{2}$ emitted by partially mined peat lands exceeds the emissions of all power plants or automobiles. The same problem exists in many countries.

The simplest way to recultivate a partially mined peat land is to extract all the peat and restore the water levels. Then, after a hundred years, the bog will be healthy again. Recultivation without extraction of decomposed peat residues is extremely complicated. Thus we need to increase peat mining, not stop it, to preserve the peat lands.

The main problem is the usage of highly decomposed peat. The higher strata are being used as a horticultural substrate, but "black peat" garners no demand on the market. At the same time, this peat contains various biologically active substances (humic acids, waxes, 
etc.) in large quantities and can serve as a source of effective fertilizers, bioplastics, medicament and absorbents.

\section{Conclusion}

And here is the point at which only scientific truth can be a solution -for this problem, all small and large problems. We must approach them from a factual perspective, even though it is challenging.

\section{Acknowledgements}

None.

\section{Conflict of interest}

The author declares no conflict of interest. 